PostGRAd. MED. J., (1966), 42, 321

Case Reports

\title{
PREGNANCY AND THE
}

\section{ADRENOGENITAL SYNDROME}

\author{
Geoffrey Chamberlain, M.B., F.R.C.S., M.R.C.O.G. \\ Department of Obstetrics, King's College Hospital, London, S.E.5.
}

\begin{abstract}
PATIENTS with treated adrenogenital syndrome are rare and those who become pregnant are rarer still. The syndrome results from abnormal steroid synthesis in the adrenal glands caused by increased ACTH secretion following a lack of cirulating cortisol. The abnormal adrenal steroids give rise to many masculinising features including the suppression of ovulation. Since 1950 when Wilkins first recorded successful steroid therapy, a number of female patients now ovulate. In 1954 the first patient with the treated syndrome became pregnant (Smith and Alvarez); subsequently occasional reports of pregnancy have appeared in the literature. This case of twin pregnancy is reported because of its interest and the effect of the high cortisol state that pregnancy has on the syndrome.
\end{abstract}

\section{Case Report}

Mrs. B.P. is a typist aged 24 years. She first presented to the Department at the age of $20 \mathrm{com}$ plaining of a secondary amenorrhoea. On questioning the patient admitted to increased facial and body hair growth while there had been a rapid weight gain for the last two years. She was an albino with congenital nystagmus; otherwise there was nothing relevant in her past or family histories.

Examination showed a plump hairy girl. There was hair on the face and breasts while in the pubic area was a male escutcheon. There was no acne or striae. The blood pressure was $110 / 70 \mathrm{~mm}$. Hg. and the heart and lungs were normal. The external genitalia were normal for a woman of her age. The clitoris was not enlarged and there was no labial fusion. Bimanually the pelvis seemed normal.

Investigations. Haemoglobin 14.3 g.\%; B.MR + $15 \%$; Plasma proteins 7.7 g. \%; Buccal mucosal smear was chromatin positive with single Barr Bodies; the 24-hour urinary outputs of 17-oxosteroids, 17hydroxycorticosteroids and gonadotrophins were $30.0 \mathrm{mg} ., 13.7 \mathrm{mg}$. and $10 \mu \mathrm{g}$. respectively (normal ranges in this laboratory being 6-18 mg., 4-15 mg. and $10-40 \mu \mathrm{g}$.). A normal pituitary fossa was seen on skull X-ray.

Under anaesthesia the above physical findings were confirmed. At currettage the uterine cavity was 7.5 $\mathrm{cm}$. long and scanty curettings were obtained (reported later as normal non-secretory endometrium). A culdoscopy showed normal looking ovaries and no stigmata of thecal over-activity were seen.

In view of the above clinical and laboratory findings a diagnosis of adrenogenital syndrome was made. This was confirmed after $4 \mathrm{mg}$. of dexa- methasone was given in a day causing a drop of urinary 17-oxosteroids and 17-hydroxyconticosteroids to $4.2 \mathrm{mg}$. and $2.3 \mathrm{mg}$. in 24 hours. Treatment with steroids was commenced, the balancing dose required being $37.5 \mathrm{mg}$. of cortisone a day in split dosage; at this level the patient began to feel better, the menstrual periods returning albeit still irregularly.

A year later dexamethasone (mg. 2 b.d.) was substituted and while on this treatment, Mrs. B.P. became pregnant, conception occurring in early January 1964. Early pregnancy was normal, the steroid dosage being maintained at $1.0 \mathrm{mg}$. of dexamethasone. By thirty weeks oedema started and Mrs. B.P. was getting much indigestion. The plasma cortisol level was $9.7 \mu \mathrm{g} . \%$ and the 24 -hour excretion rates of 17-oxosteroids and 17-hydroxycorticosteroids were 5 and $7 \mathrm{mg}$. respectively. To the dexamethasone was added $25 \mathrm{mg}$. of cortisone a day Throughout the rest of pregnancy the nausea per sisted and the patient was oedematous. No hypers tension or proteinuria occurred. Twins were diagnosed at about 34 weeks and the patient was admitted for rest, the same steroid dosage being given On 10th August, 1964, at 38 weeks, labour started spontaneously. Prophylactic hydrocortisone was given to cover any diminished stress reaction. After a 13-hour first stage, an assisted twin delivery occurred of two girls both by the vertex (birth weights 2.25 and $2.50 \mathrm{Kg}$.). They seemed uniovular and were quite normal; morphology of the placenta tended to confirm their monozygous nature.

Both mother and her infants were well and over the next few days the hydrocortisone was reduced. Mrs. B.P. requested sterilization for as well as the steroid upset, both she and her husband were partly blind They felt that two children was the limit of their family. A Pomroy procedure was, therefore, performed on the fourteenth day after delivery. At operation both adrenals were palpated and felt normal in size, regularity and consistency. Both ovaries looked normal and a wedge of one was removed. The patient recovered well from this operation and within five days was back on her pre-pregnancy dosage of dexamethasone. After ten days she was well enough for discharge from hospital

The twins were examined carefully but showed no signs of either adrenogenital syndrome or congenital nystagmus. On the twentieth day both had 17-oxosteroid and 17-hydroxycorticosteroid levels of 0.1 and $0.1 \mathrm{mg}$. $/ 24$-hour sample of urine. This is a little low but not abnormal in the neonatal period. They both gained weight on bottle feeding and left hospital each weighing just over $2.5 \mathrm{~kg}$.

Subsequent to delivery Mrs. B.P. continues well. The infants are now six months old and weigh about $8 \mathrm{~kg}$. each. The mother is a much more contented woman. Her weight is $71 \mathrm{~kg}$. (about the same as on 


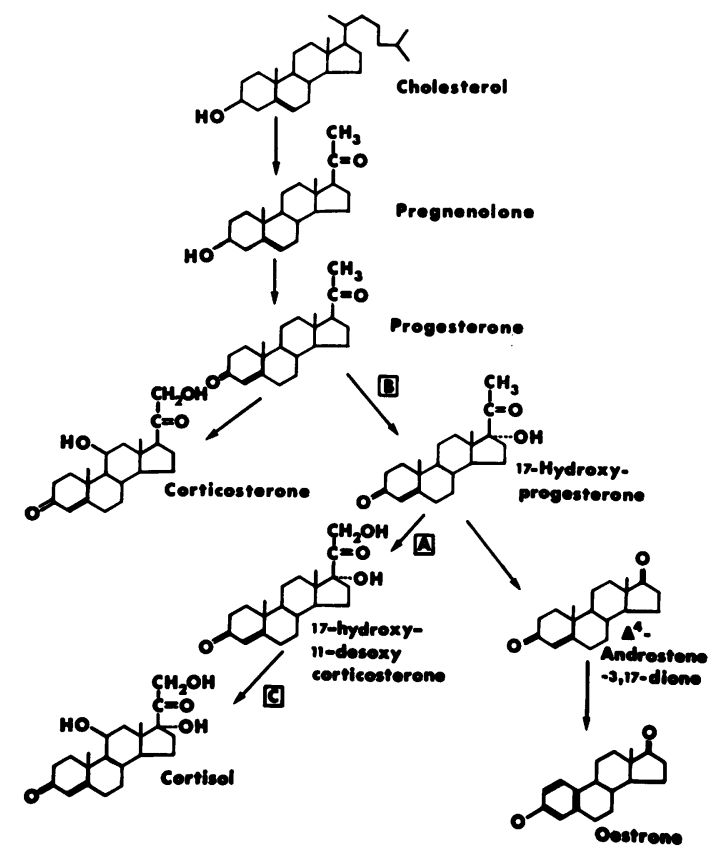

FIG. 1.-Metabolic pathways of steroid metabolism.

starting pregnancy). She is normotensive and her menses are almost regular. The hirsutism is about the same but it worries her less. Her oxosteroids and 17-hydroxycorticosteribid excretion rates in 24 hours were $4 \mathrm{mg}$. and $5 \mathrm{mg}$.

\section{Discussion}

The normal metabolic pathways of cortisol are shown in Figure 1. In most varieties of the adrenogenital syndrome, hydroxylation at $\mathrm{C}_{21}$ i deficient (shown as A on Fig. 1). Thus 1\% hydroxyprogesterone is not converted to hydro cortisone. In response to the low levels of hydrocortisone, the pituitary secretes more ACTII (Fig. 2). This has the effect of tending to restore hydrocortisone production to normal but at the same time raises the production of adren $\$$ androgens. This is reflected in the virulismo masculinisation and higher excretion of andro 5 genic break-down products (17-oxosteroids). ID rarer instances the steroid synthesis in the adrenogenital syndrome can show other variationsw Some have a defect in $3 \beta$-hydroxy-dehydrogenase (Bongiovannni, 1958) which would cause a blook at point $B$ on Figure 1, while others show deficiency in hydroxylation at $C_{11}$ (Ebevlein an Bongiovanni, 1955) represented at point $C$. Giving exogenous cortisone to these patient\$ lessens ACTH production by removing the stimulus of low hydrocortisone levels. Thus excessive metabolism of androgenic substances is diminished (Fig. 2b).

The adrenogenital syndrome is a loosely connected group of conditions differing from eact other in the severity of symptoms. It is better understood if correlated with the age at which hyperfunction of the adrenal started. In Sh\& female three syndromes may be shown.

1. Masculinisation of a female foetus ocking when adrenal hyperfunction starts intrauterine life. The infant is born with a⿳亠口冋 enlarged clitoris suggestive of a male phallus 
with the urethra opening at its base. The labia may be fused resembling an empty scrotum, and so the infant is brought up as a male. Some of this group of cases can be caused by exogenous steroids given to the mother early in pregnancy.

2. In older children the manifestations of the syndrome are again masculinising. Pubic and axillary hair appear early. Growth is accelerated but premature fusion of metaphyses with epiphyses results in eventual stunting. The body build is stocky; the clitoris may enlarge. In older girls menarche may be delayed and breast development is poor. Most of this group have enzyme abnormalities causing the abnormal adrenal steroid metabolism.

3. In adult life the adrenogenital syndrome usually presents with hair changes, oligo- or amenorrhoea and infertility. More severe cases may have enlargement of the clitoris and voice changes. Although hyperplasia of the adrenal cortex is still the commonest cause of adrenogenital syndrome in this age group, the presence of a tumour of the adrenals or ovary must be excluded. The condition is similar to the classical Stein Leventhal syndrome but differs from it in many clinical and metabolic respects (Chamberlain and Wood, 1964).

In the above account, the older classical terms used to describe the divisions of the adrenogenital syndrome have purposely been avoided. It is not possible to fit the new mass of clinical and laboratory data into the old outlines and to do so only creates confusion. The elaboration of Greek and Latin prefixes does not help the understanding of this developing field of endocrinology. The age classification presented is at least clear.

Our patient comes into the third category. She started to menstruate at the age of eleven and only later in puberty showed the stigmata of the adrenogenital syndrome. Our investigations were directed to exclude an adrenal or ovarian tumour. This was shown by the history, culdoscopy and the cortisone suppression test. Treatment was started with cortisone and within six weeks Mrs. B.P. was feeling better. The 17-oxosteroid excretion had dropped and menstruation returned. lts cyclical nature indicated that ovulation was probably occurring. This was confirmed in 1964 when the patient became pregnant. The effect of steroids was maximal on the menstrual cycle.

Our patient was an albino, a group well-known for their sparse hair. Even in swarthy individuals, steroids have slight effect only on the hirsutism for removal of the androgenic stimulus does not often cause return of the hair follicle to its original state. This situation is commonly seen in those who have been treated for the Stein Leventhal syndrome (Chamberlain and Wood, 1964) and adrenal tumours (Rook, 1965). In our case the hirsutism was unaffected by the treatment.

The twin delivery was without complications and Mrs. B.P.'s request for sterilization allowed a manual examination of adrenals and ovaries which proved normal. Histological examination of the ovary showed small follicular cysts under the surface but no other gross changes.

The infants were uniovular twins and showed no evidence of hyperadrenalism. Their genitalia were normal as were their 17-oxosteroid and 17-hydroxycorticosteroid excretions. It is believed that the defect in the adrenogenital syndrome is inherited as an autosomal recessive characteristic. On transmission the syndrome tends to follow the same pattern of age onset (Grumback and Wilkins, 1956). Since Mrs. B.P. showed a late type of syndrome we shall follow the infants' progress for some years.

Pregnancy is associated with increased adrenal activity. Plasma hydrocortisone and cortisol levels rise and this can be associated with an improvement of a cortisone-influenced disease, e.g. rheumatoid arthritis. Although this is the overall picture, a few patients show a drop in plasma steroid levels at 26-34 weeks (Gemzell, 1953) and this is reflected in the increased requirements of cortisone being given for certain long-term conditions, e.g. ulcerative colitis and lupus erythematosus. Mrs. B.P. was stabilised on the same dose of dexamethasone from soon after the diagnosis of her disease until well into pregnancy. There was some face-flushing and water retention in mid-pregnancy which was unaccompanied by hypertension or proteinuria. Dexamethasone is supposed not to cause sodium retention and it is paradoxical to note that after supplementary cortisone the oedema lessened and body weight was stabilised. Further, the effect of four intrauterine adrenals in place of the more usual two, should be considered for steroids can quite rapidly cross the placenta from one circulation to the other.

It is from such cases as these that we realise that the inter-relation of the adrenal gland with the pituitary and placenta is not a simple feed-back but a more complex system.

Summary

A patient with an adrenogenital syndrome is followed through a twin pregnancy. This syndrome is examined and its inter-relations with pregnancy is discussed.

I should like to thank both Sir John Peel and Professor John Anderson under whose combined care the patient was admitted. I am glad to be able to acknowledge their help and the assistance received from the members of the Medical Unit in this presentation.

\section{REFERENCES}

BonglovanNi, A. M. (1958): In vitro Hydroxylation of Steroids by Whole Adrenal Homogenates of Beef, Normal Man and Patients with the Adrenogenital Syndrome, J. clin. Invest., 37, 1342.

Chamberlain, G. V. P., and Wood, C. (1964): Stein Leventhal Syndrome, Brit. med. J., i, 96. 
Ebevlein, W. R., and BonglovanNi, A. M. (1955): Congenital Adrenal Hyperplasia with Hypertension: Unusual Steroid Pattern in Blood and Urine, $J$. clin. Endocr., 15, 1531.

Gemzell, G. A. (1953): Blood Levels of the 17Hydroxycorticosteroids in Normal Pregnancy, $J$. clin. Endocr., 13, 898.

Grumback, M. M., and Wilkins, L. (1956): The Pathogenesis and Treatment of Virilizing Adrenal Hyperplasia, Pediatrics, 17, 418.
Rook, A. J. (1965): Endocrine Influences on Hair Growth, Brit. med. J., i, 609.

SMith, E. K., and DE Alvarez, R. R. (1954): 3 Congenital Adrenal Hyperplasia: Adolescen $\mathbb{Z}$ Development, Ovulation, Menstruation and Preg nancy under Influence of Cortisone, J. clin. Endocr. 14, 109.

WILKINS, L., LEWIS, R. A., KLEIN, R., and RosemberG, G. (1950): Supression of Androgene Secretion by Cortisone in a Case of Adrena: Hyperplasia, Bull. Johns Hopk. Hosp., 86, 249.

\section{A PROBLEM IN DIFFERENTIAL DIAGNOSIS

\author{
M. J. SмIтH, M.B., B.S., M.R.C.P. \\ Royal Victoria Infirmary, Newcastle-upon-Tyne.
}

ARRHENOBLASTOMA FOLLOWED BY CUSHING'S SYNDROME

Cushing's syndrome has been described in association with malignant tumours of the lung, predominantly oat-cell carcinoma (Bagshawe, 1960) pancreas (Crooke, 1946) thymus (Hubble, 1949) prostate (Webster, Touchstone and Suzuki, 1959) breast (Lockwood, 1958) phaeochromocytoma, undifferentiated mediastinal tumours (Liddle, Bland, Ney, Nicholson and Shimizu, 1962) and ovary (Deaton and Freedman, 1957; Parsons and Rigby, 1958). The adrenal overactivity has now been shown to be due to the production of an adrenocorticotrophin-like substance by the tumours (Liddle and others, 1962; Christy, 1961). These patients may show the clinical features of florid Cushing's syndrome or may appear clinically normal despite biochemical evidence of considerable adrenal overactivity. Each case is usually characterised at the time of investigation by gross elevation of the urinary 17-hydroxycorticosteroids and 17-ketosteroids and a characteristic hypokalaemic alkalosis which is unusual for Cushing's syndrome due to disorders of the pituitary-adrenal axis (Bagshawe, 1960). However, Hymes and Doe (1962) investigated 55 cases of bronchogenic carcinoma and found evidence of increased adrenocortical activity without any clinical evidence of hypercorticism. It may be that some examples of this syndrome do not have the gross biochemical changes associated with the established case and that the distinction between 'ectopic adrenocorticotrophin production' and cases of Cushing's syndrome due to other causes may not be clear. The case reported illustrates the difficulty in investigating a patient with clinical Cushing's syndrome in whom there was a possible recurrence of a tumour of known endocrine potentiality.

\section{Case Report}

Mrs. J.B., a 30 year old housewife previously in good health, first developed amenorrhoea in July 1962. When she was seen in the gynaecologicaL department, Royal Victoria Infirmary, Newcastle, inco November 1963 there was definite evidence ofos virilisation. She was hirsute with male-type dis tribution of hair over the abdomen and face, breasts were under developed and the clitoms enlarged. Vaginal examination revealed a cystic lef ovary. At laparotomy in November 1963 performeda by Mr. F. Stabler a yellow cystic tumour of the ovary measuring $10 \mathrm{~cm}$. by $7.5 \mathrm{~cm}$. was found partly adherent to the posterior parietal peritoneum. A left salpingo-oophorectomy was performed. The uterus? and right ovary were normal and palpation of the suprarenals was also noted to be normal. Histology of the tumour was reported: "There is loss of: tubular differentiation. The bulk of the viable areaso show an intermediate degree of differentiation in which solid alveoli or interlacing solid cords oro trabeculae of tumour cells are seen, of ten flanked by vacuolated or granular eosinophilic cells. The appearances are those of an arrhenoblastoma."

Progress. The patient made an uncomplicated recovery. In January 1964, within two months ofo the operation, she restarted menstruation and when next seen in July 1964 she was found to be three months pregnant. The pregnancy proceeded normally until at six months she developed thirst, polyurian and glycosuria. GTT: fasting $100 \mathrm{mg}$./100 ml.; 302 ; $208,194,154 \mathrm{mg} . / 100 \mathrm{ml}$. at 30-minute intervals. N A diagnosis of diabetes mellitus was made and shen was started on twice-daily soluble insulin. In $\mathrm{W}$ November 1964, at seven months, she was delivered of a premature male child weighing $3 \mathrm{lb}$. 11 ozse Lactation was suppressed. Menstruation restarted and continued normally. In April 1965, five months after delivery, at a routine diabetic clinic follow up? it was noted that she showed slight facial mooning. 0 persistent hirsutism, a definite buffalo hump, livid striae, thin skin and a reas of bruising. 